considered them to be allied to Trigonellites or Aptychus. He divides the Aptychi into three groups, A. cornei, imbricati, and cellulosi, the former of which differs from the two latter (which are calcareous and bivalve, in being corneous and univalve, both which characters are applicable to the fossils which $I$ have above described. He supposes that in the corneous species a certain degree of motion was effected in the two halves of the body by means of its own elasticity, while in the calcareous groups the same end was obtained by means of a bivalve structure. He enumerates five species of the corneous group, all of which are from the lias and inferior oolite, and which, like the imbricate and cellulous species, are occasionally found in the interior of Ammonites, occupying a symmetrical position, and corresponding in their dimensions to the shell in which they are found. From these and other reasons, $M$. Voltz regards the whole of this group of fossils as appendages to the animals of Ammonites, a view which is confirmed by the facts adduced in the present communication.

\title{
5. Notice concerning the Tertiary Deposits in the south of Spain.
} By James Smith, Esq., of Jordanhill, F.G.S.

Is the bay of Gibraltar, immediately to the north of the plain which separates the fortress from the Spanish territory, we meet with a series of low swelling hills of yellow rubbly sandstone, the beds dipping to the S.W. at an angle of $12^{\circ}$, and abounding in marine tertiary fossils. Of these fossils, there is only a small variety, and of many of the species I could only find casts; but these were sufficient to furnish an important link, connecting distant deposits; for upon comparing them with the specimens in the Society's Museum, illustrative of Col. Silvertop's account of the tertiary formation of Murcia and Grenada, and Lieut. Spratt's paper on the Geology of Malta, I find that the three deposits are identical.

I have also observed tertiary beds at Cadiz, and between Xeres and Seville, which, I am satisfied, belong to the same deposit; and Mr. Sharpe, in his paper on the Geology of Lisbon, has assigned reasons, with which I entirely agree, for considering that the tertiary beds of the Tagus coincide with those of the south of Spain.*

In a communication respecting the age of the Lisbon tertiary beds, I stated the grounds which led me to conclude that it was nearly the same as that of the Bourdeaux deposit, and I may now add, that I consider it more ancient than the Touraine Faluns, or older crag. $t$ It will be seen, from the report of Professor

* Geol. Transactions, 2d series, vol. vi. p. 113.

+ Geol. Proceedings, vol. iii. p. 492. 
Forbes on the Malta fossils*, that he has arrived at the same conclusion with respect to their age.

Professor Agassiz, who examined my collection of Lisbon shells, considered that they were of the same age as the Molasse of Switzerland.

The whole of these deposits, therefore, may be placed in the Miocene or middle division of the tertiary system ; a formation of prodigious extent, which appears to have comprehended the whole of the southern portion of the European continent, from the shores of Portugal to the Morea, and from Switzerland and Vienna to Malta and the Straits of Gibraltar.

* Geol. Proceedings, vol. iv. p. 232. 